\title{
Why Am I Alive: A Chinese Elder's Life Narrative and Searching for Life Meanings
}

\author{
Yang Yang ${ }^{1}$, Nianqi Ye ${ }^{2}$, Tangsheng Wang ${ }^{3, *}$ \\ ${ }^{1}$ Qingdao No. 9 High School, Qingdao, China \\ ${ }^{2}$ Shanghai Shixi High School, Shanghai, China \\ ${ }^{3}$ School of Marxism, Wuhan University of Technology, Wuhan, China
}

Email address:

1132290041@qq.com (Yang Yang),2761094821@qq.com (Nianqi Ye),wangtangsheng@whu.edu.cn (Tangsheng Wang)

${ }^{*}$ Corresponding author

\section{To cite this article:}

Yang Yang, Nianqi Ye, Tangsheng Wang. Why Am I Alive: A Chinese Elder's Life Narrative and Searching for Life Meanings. American Journal of Applied Psychology. Vol. 9, No. 4, 2020, pp. 108-116. doi: 10.11648/j.ajap.20200904.14

Received: May 19, 2020; Accepted: July 2, 2020; Published: July 22, 2020

\begin{abstract}
This paper mainly adopts the method of participatory observation to conduct behavioral observation and in-depth interview on a 90-year old man in nearly one and a half years. Observation records and interviews the text analysis, according to the case for the old man has a distinct personality characteristics, she end up very value personal free will and give full play to the individual, for lover, husband, daughter and other important others keep a more distant relationship, these life experiences brought her positive feelings at the same time, also makes the meaning crisis - year period of life. The conclusion is that the theory of sense of control and the positive effect of aging do not help to solve the problem of the lack of life value of the elderly in China, and only by establishing the interpersonal relationship closely related to survival and the pursuit of cultural identity in the field of life can we get an answer that meets the needs of the parties concerned.
\end{abstract}

Keywords: Participatory Observation, Alive, Relationships

\section{The Introduction}

This paper will describe and explain the life world of a Chinese senior citizen from the perspective of social psychology. In the previous study, the researchers used bibliometrics to reveal the development of the research in the field of geriatric psychology in the past 30 years [1].

Firstly, in Chinese literature (CSSCI), the research focus on the psychology of aging lies in the word "support" [2], such as family endowment, social endowment, home endowment, endowment mode, etc., which shows the relationship between the giver and the receiver. In terms of how to provide for the aged, it involves a lot of considerations about the living mode, living arrangement, rural areas, cities and other fields where the old-age care relationship takes place, as well as social support, intergenerational support and other related resources, as well as individual feelings such as subjective well-being and life satisfaction in different old-age care relationships. In the English literature [3], the topic is more negative emotions associated with aging vocabulary, aging is associated with a variety of mental illness, aging research with children, teenagers, adults and other development stage of study, as the rest of the population aging studies is the reference rather than focus on goals, about elderly such as nursing, death, and other relatively weak.

Secondly, in terms of the basic research topics, the research of Chinese literature is basically macro, but it focuses on the core concepts of psychology such as quality of life, life satisfaction, mental health and cognitive function together with the English literature. However, there is a great lack of research on emotion. And in contrast, English literature, may be due to psychological term most comes from English, so the key to the neo-Confucianism in the center of the English-language literature concepts appeared in the high frequency keywords, but cultural, spiritual, and family and so on three daily in 1992-2018, the concept of web of science senile multiple occurrences of psychology is the study of literature, whereas in Chinese literature has been hardly any attention. From psychology, China has been following the tradition of western academic, cultural, spiritual and family, is likely to be older psychology research in the future, but if China directly use these western academic research path (research approach), the lack of 
a bottom-up research for China's old people psychology and behavior, may be lost in cut situation [4].

With the rise of China's economy, the cultural exchanges between China and the west are more frequent, and the cultural variable is bound to become more and more important in the field of Chinese psychology. In addition, in the Chinese cultural tradition, family is originally an important psychological object, and the meaning of family related to the elderly in China undoubtedly has important cultural connotation, so it should also become an important theme in the psychology of the elderly, but the research approach may be significantly different from that in the west. About spirituality, belongs to the meaning of life, is the most often think of old people daily objects, although is serious in Chinese current research to ignore, but did not influence the old people to the search for meaning in life, most of the old man often has a distinct cultural characteristics to the behavior of the search for comfort, such as writing brush calligraphy, listening to the national opera derived from ballad singing, playing mahjong, tai chi, qigong practice and so on [5].

Finally, analyze the research the assumptions behind, it's not hard to see, in the English literature, the research need to try to eliminate the investigators and the relationship between the respondents, because the relationship can affect the result of the investigation, but, in the field survey and especially China old man's survey, respondents from Chen report along with the changes in the relationship with the investigators, in the face of an acquaintance said is complaining, suffering and sorrow, rather than to act as positive and optimistic to strangers. English study to aging views the it as a process and denied the existence of an elderly stage [6], but the old people in a nursing home is not just a continuous aging process, and it is a group of old man lose the ability to live independently, to be round-the-clock care institutions, this is a stage, for the old man can't deny the fourth age stage is common in elderly. Everyone will lose the ability to act or even make decisions. At this time, the old people have no distinction between success and failure, and can only rely on the actions of other actors. Therefore, the interpersonal relationship of the elderly (parent-child relationship, social attitude, hospice care, death education) is probably the most important research topic in Chinese aging psychology.

To sum up, in the context of globalization, if the research on aging psychology in China continues to follow the research paradigm of aging psychology led by the United States, it will not be conducive to the combination with the practice of aging and the development of action research. This paper starts from exploratory research. According to the original research design, it should enter the site with an open attitude without any presupposition, find problems, put forward hypotheses, and finally verify hypotheses. On the basis of long-term participatory observation, this paper will sort out the local resources of China's old-age care, especially the psychological adaptation strategies, and make a comparative analysis with reference to the prevailing research concepts in the academic community, in an attempt to discover the uniqueness of the Chinese elderly living world as much as possible.

\section{Methods and Procedures}

\subsection{Methods}

The current study adopts the method of ethnographic psychology. Ethnographic psychology is a kind of research method based on participatory observation, which need researchers to use informal strategies to work, integrate into the group culture, learn local language and having conversations naturally according to context [7].

Participatory observation rate was a gradually deepening process, and mutual understanding with the aged followed a natural process and chance. In the first step to contact the aged in the research level the author did not follow the interview outline drawn in the previous researcher's documents. Instead, he/she went to the site through the introduction of the door man (the director of nursing home) as a member of the psychological volunteer team to carry out the work at least one working day a week. He/she spent quite a long time to let the aged know that the volunteers would provide some psychological consulting service and psychological research for them. It took about half a year for the aged to understand and accept the identity of the volunteers.

One year later, the aged became accustomed to the volunteers. As one of the volunteers, the author was gradually able to "understand" their language and became one of the members of the nursing home to work and live with them. In this process, the academic assumption, daily stereotypes, personal prejudices and psychological complexes about the aged were gradually clarified and changed, while the behavior of the aged gradually changed from vigilance, deliberate performance and role playing to natural performance. In this process, the themes in the daily life of the aged were gradually sorted out and their emotions and feelings were able to be sensed from their words and deeds, in this way a cooperative relationship which was helpful in consultation and research works was established. Discussions even involved some more in-deep topics. The analysis coding about speech texts of the aged is R-201XXXXX (date)-X (name)-X (serial number).

The staff of the nursing home plays an important role in the daily life of the aged. They provide the aged with the social support, which has the same the function of a traditional Chinese family. Therefore, the reports by the nursing staff during the observation period were also used as part of the research data. In addition, nursing staff was responsible for the daily caring, while researchers played the role of psychological consulting volunteers. The activities of researchers themselves also formed part of the research materials. These data are mainly included in the viewing logs, coded D-201XXXXX (date)-xx (name).

HML is one of the people the volunteers interact with most at the nursing home, talking to her almost every time she visits. One is that the volunteer office is on the third floor, and HML also lives on the third floor, so it is not convenient to go downstairs, so it is convenient to have a chat with the volunteers. Therefore, we chose HML as a case study.

Since Selecting HML as a focus observing subject, it had taken about one and a half years to complete this process. The 
authors analyzed information collected during participatory observation, interview, and longitudinal study, adopting methods of grounded theory and discoursing analysis. Based on that, researchers extracted and summarized the topics she cares about in her daily lives, discovering the key features of her life world.
Since the researcher met with HML for the first time on March 14, 2016, and she left the nursing home after the last meeting on June 25,2017 , the researcher met with her a total of 36 times, with an average of 2 to 3 times per month, and the duration of each chat ranged from half an hour to two hours, as shown in table 1.

\subsection{Procedures of Participatory Observation}

Table 1. Examples of the interview process and basic content.

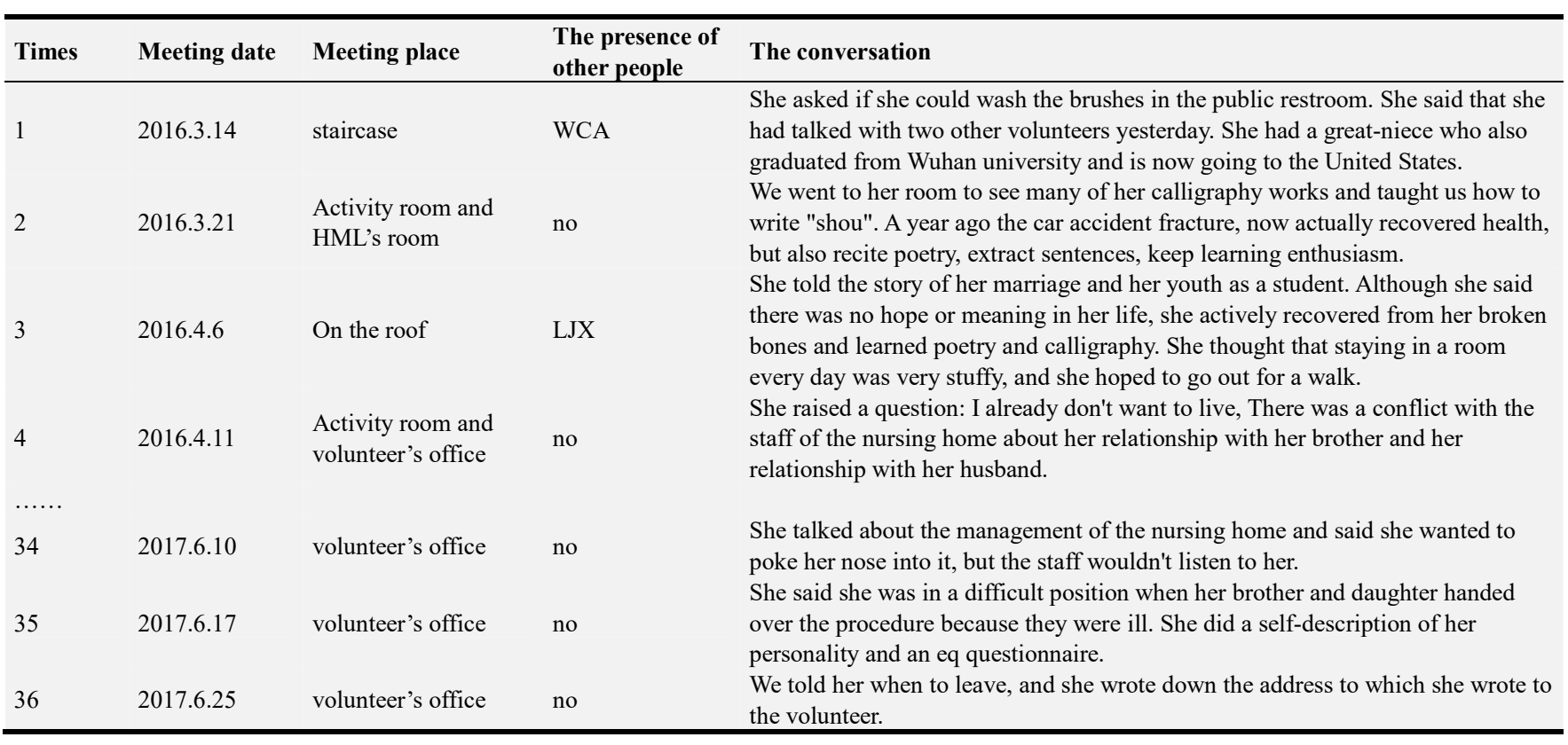

\section{Result}

\subsection{An Overview of HML's Life History}

HML, who was admitted to the nursing home to recover from a broken bone in a car accident a year ago, is now in good health. She has been observed to recite poems, extract sentences and keep learning habits. In the previous three conversations, she learned about HML's marriage and the history of her young student life. She thought it was very boring to stay there every day and liked to go out for a walk.

HML has a total of six siblings, brother and sister have died, leaving the second brother still alive. In the fourth conversation she asked, "what if I don't want to live anymore?" She talked about the current spat with the dean, who she said restricted her freedom of movement because of security concerns, and another staff member who she said was hypocritical and unwilling to deal with.

She put all the property of the second brother there, although he listen to her sister-in-law instigated, but has now been put down by him to the heart, anyway, that's it, she also has a salary (pay check in the big brother's daughter, the niece was kind to her, her brother had died, is the central China normal university middle managers) property right there, want how to do how to do it. She seemed to suffer from her relationship with her caretaker.
Later in the interview, we learned that she was born in 1921, in 1946 graduated from high school, high school is to fall in love, talked for many days, and the results are both not admitted to the university (undergraduate), later on the junior college, assigned to the Guangxi in 1951, our daughter was born in 1958, 1961 divorce from Shanxi to return to Wuhan, though her husband is good to her, but because her husband rightist stricken, spending spree, they divorced, then has been alone. Although she finds it hard work, it's worth it. She feels like she's been here for more than 30 years, and she always feels like she's at the same age. She feels that she is a composite of all kinds of contradictions. Even though she has no love in her life, there is nothing that she could not pass. She has a salary and can pass 90 years old with (plus) $200 \mathrm{rmb}$. Such is her own character. She thinks her past story and life experience can be used for reference, for example, reading books can't fall in love, easy to delay learning.

On April 15, 2017, HML told the volunteers that her daughter had come over from Shanxi, that her ex-husband had been dead for four years, and that she was going to pick her up. She showed a mixture of pleasure and embarrassment. She said the money was now with her brother, her guardian, because of the property and custody issues. She didn't want to get involved in how they negotiated or litigated. Of course she was glad to have her daughter, but the trouble was that she was often disobeyed. 


\subsection{Analysis of the Contents of Interpersonal Relationship in the Text of the Interview}

\subsubsection{Interpersonal Content, Including Family Relationship, in an Interview with Greatest Space}

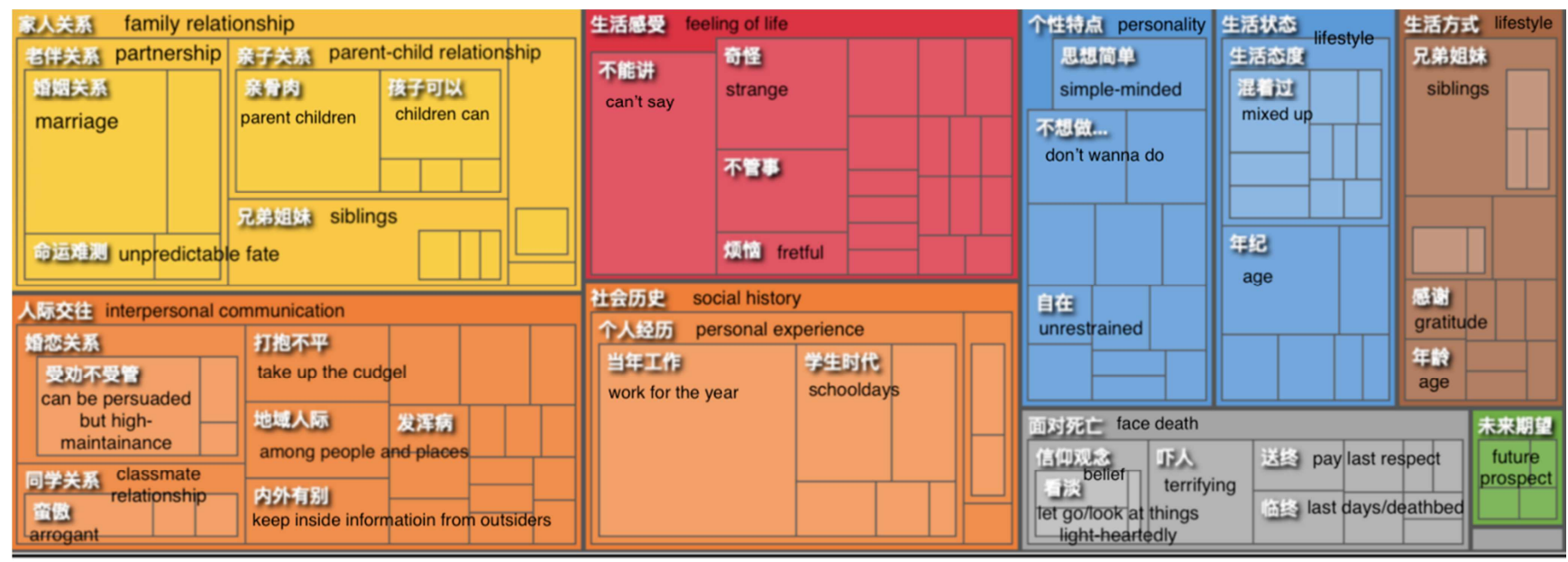

Note: The area of the node represents the coverage of its content in the interview materials.

Figure 1. All nodes compared by number of coding references.

Huang went through a broke-up because she didn't want to be restricted by her first love, and she didn't want to be held back to the role of a housewife doing domestic chores and having children. When her daughter was 3 years old, she divorced and went back to her native place, not for fame and power, but for freedom and learning. For now her daughter takes care of her as she has to face up to the final days, accepting the advice of others and her daughter's kindness.

Because her daughter is of her blood, she can be relied upon when she finally loses her mobility. Property is not that important. Once when the volunteer was chatting with HML, people of management would come in and say that XSD was confused so there is no point arguing with her, and that was when Huang brought up that it was because XSD was abusing her, she was only defending herself. That was mainly because his brother said that XSD's clothes was nice with a flower, once her brother left, XSD hit her with a cane. She said that she once told her roommate XSD that dirty things should not be left in bed because they were contagious, but XPP's daughter said it was none of her business. She thinks XPP has a troubled brain and should never have been sent to the nursing home. (D-20160509-HML-07)

HML didn't get along with another roommate, JPP, either. Their relationship was fine at first, but JPP was too clingy she kept adding food for her and had to keep her company watching TV, which all annoyed her. After a big fight, JPP left the nursing home. (D-20170204-HML-02)

She maintains a good relationship with the WCA and MZR who live downstairs. She always borrows books from Wang. She thinks it was a good idea to ask Wang to buy the books for her. Wang keeps a lot of books in his study and Huang once borrowed one of his books called Being Your Own Psychiatrist. She said that it could be busy every day, reading and writing. When talking about studying, she mentioned a retired teacher of $\mathrm{W}$ college of liberal arts in the university of the elderly named Zhang Shan. She said that Zhang was so good at teaching that everyone hardly ever wanted the class to be dismissed. There is another teacher from their junior high, graduated from Jinling women's college graduates. Huang said that she was good at teaching about Si Shu. The lectures and classes are in English. Wang also helps to buy newspapers and send letters.

May 2017 was the transitional month for HML to leave the nursing home, saying goodbye to Wuhan, and go to Shanxin. During this time, she fell down on and injured her waist. While in physical pain, she was dissatisfied with the nursing home's activities such as birthday parties and calligraphy sessions. There were also nutrition and heath-care problems. She had doubts about the objectives of the volunteer's consulting and research work here, and Huang thought this should be evaluated. Huang sent copybooks to the nursing home's mental health counseling volunteers and said she had them prepared for the staff whom she had a pleasant relationship with. She often asked Wang to borrow and buy books for her.

\subsubsection{As her Guardians, Her Second Brother and Her Daughter Have the Most Important Influence on Her Living Conditions}

As mentioned above, at the beginning of the observation, HML took her second brother as the guardian and left all the property (mainly the house demolition fee) to his custody. Although she said that he could do whatever he liked, she still had a vague sense of insecurity,(D-20160411-HML-02) which was revealed when she changed her legal guardian to her daughter:

"My brother has expressively said he wasn't able to manage my pensions. To be honest, my pension is just the house I used to live in which belonged to Housing Administration. So by 
definition, I should never get the money, no? It is not my house because I didn't pay for it. I was just paying rent every month. And there was the relocation compensation, it was considerably quite a lot, you know." (R-20170422-HML-10)

"As for the money issues between us... well... It was not that simple, I'm telling you that." (R-20170617-HML-18)

"I'm gonna tell you this: for instance, if I had a sum of money and I handed over to him, it was eight thousands for a fact but he would say six thousands. Would you file a law suit against him? This was just one time. The second time, again with the money, he said I never have given the money to him. What was the deal about that? I would just solve these two problems but what suggestion you you have to solve them? What should I do? The problem is real, I'm telling you, but there's no way to solve it. I was thinking, my brother, all of my money was in his control. He took care of my money no matter I live or die.” (R-20170617-HML-28) Huang thought her brother would be in charge of her pension until she dies, so she wouldn't worry about it. However she did not expect her daughter would come to fight for the right to support and her brother is also quite old would health issues, so the guardianship needs to be changed:

"They all think I'm too old. Though I still can move around, but what about when I can't? That day would come eventually, I think for myself."(R-20170422-HML-32) This transformation not only brought the conflicts between HML and his second brother to the table, but also caused the relationship between HML and his daughter to change from the root. When her daughter was not the guardian, the mother-daughter relationship was independent and it was without interference in each other's life.

"She's okay, my daughter. Although she's not going to school, but she's okay in principle, and she doesn't bother me, and I don't bother her." Huang laughed. (R-20160411-HML-52)

Because Huang had been living in Wuhan for a long time, she didn't want to go to her daughter's in Shanxi, but her daughter is the only family member now she's in her old age.

'I'm telling you, I didn't want to be in Shanxi, either. I didn't want to go there, to be honest. But, but the only family I have is there, and it wouldn't be right if I didn't go. It was like... it was kind of difficult." (R-20170422-HML-04)

This "only family" meant a last resort, but her daughter had always been an "outsider" until she took over the role of guardian from HML's second brother:

"She... (emphasizing) she belongs to somewhere else. She's not on our side. My brother and I are on the same side, and she is on her own side." "My girl, she is not at all, ha ha, she, she is really an outsider, for us, me and my brother, and she is not one of us. So how could she be in charge of our business, right?" (R-20170617-HML-08)

According to the feedbacks after HML moved to her daughter's home in Shanxi for half a year, Huang was not doing very well there. She wrote to and called GXF saying that she was like a living dead person. She did not understand the Shanxi dialect people speak here and could just wait and die alone. GXF said that at first she was seen as a positive model there, but that it was wrong for her to be alone and not live with other people. Her daughter came to visit and she still liked to lecture her, and it was not pleasant. Nurse Chen said they were not in a good shape those days, not to mention the days afterwards. Her daughter said whoever came here speaks the Shanxi dialect and it was okay that she did not understand. It was supposed to be like this (D-20171126-GXF-2). GXF's words were backed up by the director of the nursing home, WL, who said HML was still alive and had sent festival cards over the New Year. Once Huang had a quarrel with his daughter and called him to bring her back (D-20180314-WL-2). WL explained the possible explanations from his perspective:

"She felt like home here. She could at least do something. But when she went back, it felt like she wasn't in charge of her own life, like, you couldn't get a sense of autonomy in her writing." (R-20180422-WL-30)

\subsubsection{After Getting Familiar with the Researchers, More Negative Feelings Towards Life Were Discussed}

For more than a year, Huang has always been very willing to communicate with the volunteers. She would actively lead the volunteers to her room, to the rooftop and to other people (such as MZR) for interviews. She would always find a reason to come to volunteer office and chat. For example, she would say that she remembered something that we could keep in our record for analysis, or she had some questions and concerns, or just to tell us where to get a good deal for groceries, or rush us to leave early, because of the heavy traffic during peak hours, then she would talk about her feelings and life.

If there are new volunteers (like HMS) into the field observation of the nursing home, she was still excited to tell her previous story, such as her love story, her marriage, and her separation from the children. She still thinks that the marriage failed because of her husband. After she became close enough to the researchers, she admitted that she wouldn't remarry because she didn't want to do household chores and didn't like living with anyone else, because others would invade her private space and bother her:

"Well, I don't want to get married, I don't want to do chores, I like to sit in the office and the library. And I can, usually in school, I do library management, and that's extremely comfortable, I like doing that." she laughed. (R-20160411-HML-56)

"I'm quite different from others, I like quiet, so the unit gave me a house for two people, and I lived alone, I can write when I'm free. If he (husband) occupied the place, I can't write. Now I have the time to write, I don't when I'm busy. And he's not saying a word about it.”(R-20160411-HML-57)

In the first month of the researcher's observation of HML, she had always emphasized the benefits of living alone and her pleasant experience: "I'm always on my own. So when I'm in the house, I do everything on my own, I'm on my own no matter where I live, and I'm comfortable with that," she laughed, "I'm really comfortable, to tell you the 
truth."(R-20160411-HML-2)

After meeting the volunteer for two months, she would mention that she was not in a good mood, but she was not all negative about things. The house she had lived in for years was torn down. Her second brother thought she didn't have any children who needed a house, so he didn't return the house. But home is gone, and Chinese people put heavy values on the concept of home. It was not as comfortable in the nursing as at home.

Although she is still practicing calligraphy, she always felt somehow uncomfortable. She would say with a rational smile: "I don't want to live at all, but I don't want to kill myself, either. "She said she may seem not care, but there is a problem, she had a psychological problem. It's a little paradoxical to say, but these thoughts are real, most of them don't come true, many people think about suicide, but few people would really do it, it takes a lot to take real action (D-20160509-HML-04). After meeting the volunteers for three months, she shared some pessimistic views about her life experiences:

"I really missed the time when we were in high school. It was so much fun. You play with friends and do things. Actually, I don't care much now, honestly. In the past it was not to let people think. Back then when the classmates were together, I don't really talk to no one. I was always alone in the room. There was nothing to say." (R-20170611-HML-15)

"I don't have a home of my own. People always say that old people should have a home. I'm not concerned with money, but I don't have a home. It's a bad thing, I always feel like I'm doing a bad thing."(R-20160606-HML-41)

"Doing these bad things on my own, again I don't have a person to talk to. I don't have the right person to talk to. Like, you are you, I don't really know you. When I talk to you, you don't know what I'm talking about. So there's no point talking at all." (R-20160606-HML-42)

After one year of observation when familiarity and trust was established, the researchers would ask some specific, sometimes tough, questions to explore her inner world, such as what the main reason for her divorce was and why she had not found a partner for so long. Her answer was:

"I don't want to be a housewife, I don't want to cook, I don't want to have babies [laughs]. I'll tell you the truth, I just want to do something and it's easy [laughs]." (R-20170422-HML-78)

After expressing these feelings, she often feels that she was tricked to talk and that she shouldn't have said many of it. Just like her thirty or so diaries, they should be burned and never known. (R-20170422-HML-79)

Before HML left the nursing home, many students came to the nursing home for internships and talked to another elder named MZR. When HML saw that she was not interviewed, he gently blamed them for not interviewing her as agreed. The volunteer thought she felt left out and comforted her for a long time. It is in a close relationship like this that she would express her inner feelings.

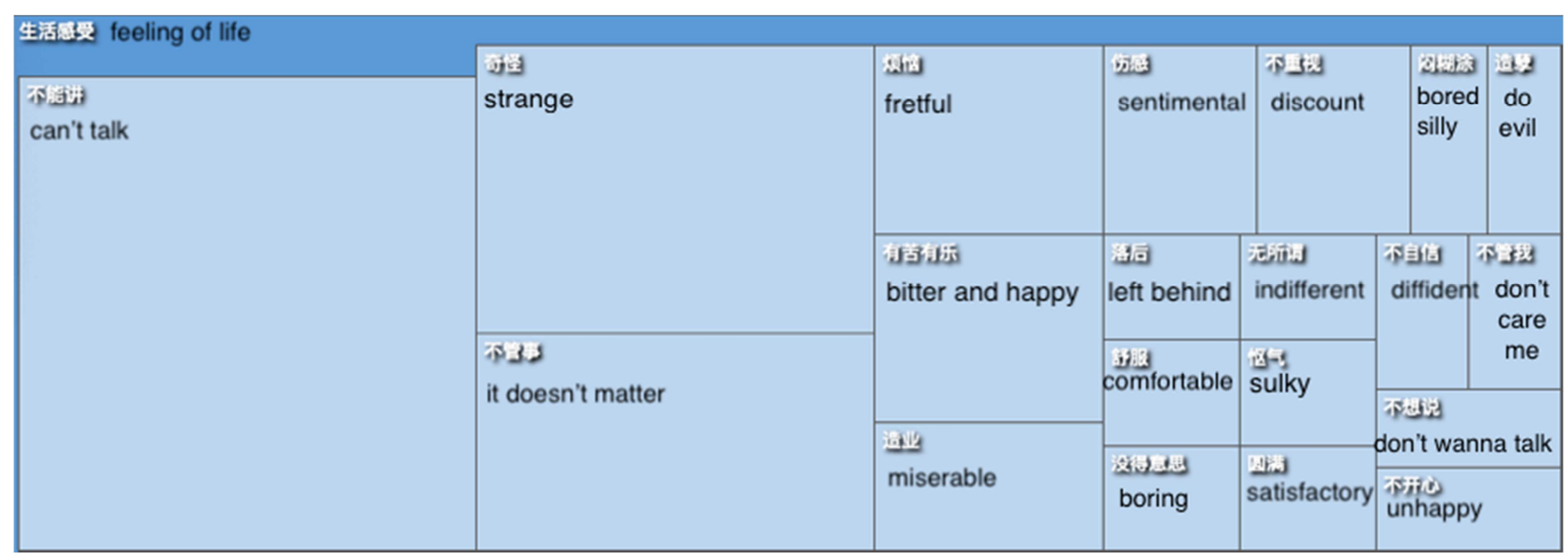

Note: The area of the node represents the coverage of its content in the interview materials.

Figure 2. Nodes on living feeling compared by number of coding references.

One could see that the HML feeling about child of the node is mainly negative emotional experience, inability to speak, standing aside, annoyance, sadness, doing good, doing bad, falling behind, not caring, being sulky, boredom, don't want to say, unhappiness, little self-management, lack of confidence, confusion; there are also some positive experiences: satisfaction, comfort, but it was only about previous, few are new experience: strangeness, bitterness and happiness, it doesn't matter. Inability to speak, strangeness and not caring occupy a large part of the story.

\subsection{As a Special Behavior of the Elderly Living Under the CHINESE Culture, HML Has Been Shown}

\subsubsection{Cultural Implications of Longevity for the Elderly}

There is a difference from western culture under the People's Daily habits, the old people in nursing home is not taboo asked his age, for the elderly in the pension institutions, be happy for the first time they met, they take the initiative to say their age, and tend to be larger, on the one hand, he (she) looks much younger than actual age, on the other hand, the social system are more 
treat - year - old man (pension will increase).

Although HML often says, "I don't want to live anymore, but there's nothing I can do about it." (D-20160411-HML-01) "but she was proud of her age. HML said that her age on her identity card is smaller because she went to school late. She was born in 1921, but her identity card showed it was 1926 (D-20160411-HML-07). The elders like to give a bigger number on their age not only because they want to get subsidies for their advanced age, but also because Chinese consider longevity as a blessing. Advanced age represents success of life. For instance, HML took researchers to her room to see her calligraphy works when they met for the second time. She also taught researchers how to write the Chinese character for longevity (D-20160321-HML-02).

\subsubsection{HML Has Distinct Personality Characteristics}

We can see from figure 1 , the personality characteristics of narrative, as an important HML coding the parent node, occupies more space in her daily chat, which occupied most space of child nodes include: thought simple, don't want to do household chores, bad-tempered, proud, work conscientiously, etc., this is her descriptions of their own personality.

She thought in high school is free, diligence, work hard to learn English, face saving, good performance, she do three times as the chairman of the committee feel interesting, systematic, she quarreled with the teacher in charge, pride perverse, to join the party did not develop successfully, despise the general school graduating from high school, at work is to study technology, later admitted to cotton yarn and cloth in spite of the work of the company.

HML's marriage was arranged in an organized way. Although her husband was smart and learned English, his destiny was in control. Her husband was labeled as a rightist, and when he turned right, he was extremely proud and complacent. Though he had been kind and considerate to her, she had been implicated and made a rightist member of the family, and she had been looked upon differently, and had to be divorced.

"I can't help saying it, because I'm involved in these little things. In fact, I don't want to, I don't want to, I never have. Really, I mean it. He is really very kind to me. But you can't forget my nature for that. Then I won't do it, then I won't... You can't do it without going this way. This is the way to go." (R - 20160406 - HML - 21)

This personality may come from her family of origin, from the personality from childhood. When HML talked about her early memories, she said that as a child, she was always crying and stubborn. She quarreled with her older brother and was sent to her grandmother's house. The family members are able to read, her father is very proud, learning foreign languages, as a doctor to earn money, for the children to read. The younger brother was clever and joined the party (D-20170527-HML-2).

\subsubsection{Ambivalent Attitude Towards Death}

HML has arranged its death in many ways. She bought her funeral supplies in advance:

"I didn't smell till the day before yesterday. I called my niece over, and I bought a nightgown at the supermarket, and I said it was better for my sleep, and I said it was better, and I don't know, it wasn't cotton, a pair of white socks, a pair of white shoes. After I bought it, I opened the cupboard the day before yesterday, wrapped something up, and put a list on the top of it. It was a list for dragging away dead people, and I was going to put the list there. "(R-20160606-HML-34)

She plans to donate her body:

"I always think, I can't find a way to die, I always think, you know, unfortunately, I thought the day before yesterday, I got that, I opened the key, it's still there, my Red Cross thing, the book, I'm not dead yet." (R-20160606-HML-35)

She even told people to drag their bodies more quickly so they wouldn't be seen badly:

"I said, Mr. Wang, I'm dead, and I need to get it done quickly, so I said, call them and ask them to tow it, don't make it close, close, no... Tight, others see bad, the end is over, do tight pretty good "(R-20160606-HML-36)

HML is always wondering what happens after death:

"I love to think about these things, how to do, I just love to think, after I died, what kind of, love to think about these things, always love to think, think of no fun, and no fun" (R-20160606-HML-37)

The conclusion is that man dies of a gust of wind:

"You don't need to think, the person is dead, you have what matter, the person is dead a gust of wind, you write down this to me, this special memory" (R-20160606-HML-38).

But when faced with death, she was not without fear. Her roommate died next to her in the middle of the night, and although she was able to face it relatively calmly and wait for the staff to deal with it in the morning, she still felt frightened after a few days and complained to the nursing home's management:

"You don't care about me? How would you feel if you didn't ask me? You, in fact, I was a little scared. "(R-20160606-HML-1)

\section{Conclusion}

This article tries to answer a key question of the elderly through a case of life narrative: I don't want to live for a long time, but what can I do? There is no reason to commit suicide, but what is the reason to live?

In this case, the value of life is mainly reflected in the individual's free will and ability to play. According to McAdams [8], the analysis of life story can start from four nodes: early memory, low point, turning point and high point.

HML attaches great importance to independence, likes learning, especially learning English, early memories in the life the first climax, namely in high school she learned English very well, had a good relationship, the first low point is she turned, with the teacher in charge not to join the party, the turning point is her exam in spite of themselves in work, the second low point is her into a marriage full of twists and turns, the turning point is a divorce, what can do, can make money, feel comfortable in one's life, agreement is implicated misjudged cases in his later years was rehabilitated and freed, elderly university on the 30 years after retirement, free. The 
highs and turns of her life were all related to her personal abilities, choices and struggles, which made her feel "comfortable" and "complete" when she recalled her life.

She likes a free and easy life, so when she is young, whether it is with her ex-husband or with her daughter, she has an attitude: I don't care about her (him), she (he) doesn't care about me, whatever. It freed each other and gave her a personal experience of happiness. But living into old age was a severe test for her: she had lost much of her personal capacity, her freedom of movement was restricted, her lifestyle choices were not up to her, and her guardians and caregivers were both a source of support and pain.

\section{Discussion}

Throughout her life, HML had conflicts with her lover and husband when she was young, experienced separation from her children in middle age, and lived in a nursing home when she was old. Is this a special case or a common phenomenon? At present, the research path of Chinese geriatric psychology lies in the interpretation of western geriatric psychological theory to the psychology of Chinese elderly, such as perceived control [9-11], positive effects of aging [12], etc. For the case study in this paper, these theories cannot explain and solve the problem of HML well.

First of all, if the reason for living is connected with the enhanced sense of control, it will only lead to the conflict between HML and the guardian and caregiver, because she is used to being on her own and not relying on anyone else. The problem is that her health has repeatedly been in trouble, and there seems to be no better choice but to rely on her second brother or daughter. The old man's sense of control through ascension to search for the value of the old man's life may have originated from the western culture and social form for the role of the old man set [13], under the Chinese culture, the respect of young people for the elderly and filial piety is enough to make the old man has a sense of control, the problem is how to these young people live in harmony.

The idea of positive effects of old age was seriously challenged in this study. In the early stage of the interview, the old man presented relatively positive and calm life feelings, but if he had in-depth contact with the researcher, he exposed more negative life feelings.

If there is a positive effect of aging, it is likely to be a psychological defense strategy of aging that may change with the familiarity of the relationship between the researcher and the subject.

The theory of sense of control deprivation and the theory of positive effects of old age are probably the researchers' expectations of the life of the elderly according to the language of the mainstream society or the mainstream academic category, and the reactivity of the elderly in the situation leads to the "discovery" of the researchers. In other words, most of these findings may be due to the lack of close proximity of language to the old people's life scenes, which is an artificial psychological phenomenon.

Buehler [14] and Rosow [15], because the characters of old people (gender, career, and even family) gradually lose, the old man's self-concept should become negative, after into old age, self-concept in social attitude, self-control and hostility appeared significant change [16], but the old man can use comply with the policy [17], Adjusting goals and expectations [18] and transferring energy to inner life [19] are the methods people often adopt in the face of social changes.

Sheila sheu et al. Studies have found that the ability of China's elderly had significantly lower self [20], wu orchid argues that beneficial to the role of the old self identity and accept their subjective well-being [21], the ability of HML self and self-role not agree may reduce its subjective well-being:

"... Madam, you still want to do nothing, you are now ninety-six and ninety-seven, he said you still want to do nothing, which means I'm already in the dirt... So when I think of it, I'm angry." (r-20170422-hml-52)

In HML's own words, she thinks she is always good to do bad things: "the worst thing I can't do in my life is to be too straight, I can't help but say (others), but people are always asking for good, to be good to others, the result is like this, you say survival is interesting?" The value of the life she found was not in enjoying one's own life, showing one's own proud abilities, but in helping others. But some people are so deep in their heart that they are "straight" and "simple in their thinking" that they rarely are. Of course, it also helps her to talk directly to volunteers and others. Her desire to live, or lack of desire to live, may be rooted in the task of establishing intimate relationships with significant others that she failed to accomplish in her youth. By choosing her as her guardian at an advanced age, she may be able to find a satisfying answer in the conflict and integration between her and her daughter.

Besides, in Chinese culture, longevity is a blessing. Longevity, also known as yangshou, the last day, in the Chinese tradition seems to be doomed by fate, the opportunity of heaven can not be revealed, also can not be violated. In the Chinese concept, longevity is often used as a blessing for the elderly, so longevity is basically closely linked to happiness. Because the Chinese people give full respect and preferential treatment to the elderly, especially those over 100 years old, the elderly people often report their age is inflated [22]. This is a cultural reason for China's elderly to keep going. HML loved English in her early years, but in her later years she often practiced calligraphy and read traditional classics such as ancient books, in which she must have obtained many of the answers she wanted.

\section{Acknowledgements}

Supported by "the Fundamental Research Funds for the Central Universities (WUT: 2020VI022).

\section{References}

[1] T. Wang and C. Hou."A Topical Structure Analysis on Chinese Aging Study and Practice in the View of Culture Psychology". In Proceedings of the Second Summit Forum of China's Cultural Psychology, T. Xie, L. Hale, and J. Zhang, Eds. America: The American Scholars Press, 2016, (pp. 164-170). 
[2] Nanjing University, C. S. S. R. A. C. (2016). Chinese social sciences citation index. Retrieved July 15, 2016 from NJU in China: Institute for Chinese Social Science Research and Assessment. Website: http://cssrac.nju.edu.cn/index.html.

[3] Library Wuhan University. Web of Science (including SCIE, SSCI, A\&HCIM CPCI). WHU in China. [Online]. Available: http://iras.lib.whu.edu.cn/ index.html

[4] Wang, T., \& Yu, Z. (2018). The Study on Aging Psychology According to the Elderly Care under the Glocalization Perspective. International Journal of Culture and History, 4 (4), 109-113.

[5] Wang, T, Guo, Z. \& Zhang, Y. (2019). The Social Construction of the Senile Dementia Based on the Self-Statement by an 80-year Aged. Advances in Social Science, Education and Humanities Research, 298, 317-325.

[6] Neugarten, B. (1996) The meaning of age: selected papers of Bernice L. Neugarten. Chicago: The University of Chicago Press.

[7] Wang, T., Qian, S., \& Zeng, Y. (2018). A Study on the Life World of Chinese Elders with Assisted Caring by Institutions: From the Perspective of Ethnographic Psychology. Psychology and Behavioral Sciences. 7 (3), 62-68.

[8] McAdams, D. P., Hoffman, B. J., Mansfield, E. D., \& Day, R. (1996). Themes of agency and communion in significant autobiographical scenes. J Pers, 64 (2), 339-377.

[9] Langer, E. J., \& Rodin, J. (1976). Effects Of Choice And Enhanced Personal Responsibility for Aged - Field Experiment In an Institutional Setting. Journal Of Personality And Social Psychology, 34 (2), 191-198.

[10] Rodin, J., \& Langer, E. (1980). Aging Labels - the Decline Of Control And the Fall Of Self-Esteem. Journal Of Social Issues, $36(2), 12-29$

[11] Rodin, J., \& Langer, E. J. (1977). Long-Term Effects Of a Control-Relevant Intervention with Institutionalized Aged Journal Of Personality And Social Psychology, 35 (12), 897-902.
[12] Wu Lin and Xing xiaoli (2009). Positive effects of attention and memory: the aging paradox and the theory of social emotional selection. Advance in Psychological Science (02): 362-369. (in chinese)

[13] Atul Gawande (2015). The best goodbyes -- what you must know about aging and death. Hangzhou, zhejiang people's publishing house (in chinese).

[14] Buehler, C. (1968). The general structure of the human life cycle, in C. Buehler and F. Masarik (Eds.), Human life: A study of goals in human perspective. New York: Springer Publishing CO.

[15] Rosow, I. (1974). Socialization in old age. Berkeley, CA: University of California Press

[16] Pierce, R. C., \& Chiriboga, D. A. (1979). Dimensions Of Adult Self-Concept. Journals Of Gerontology, 34 (1), 80-85.

[17] Brandtstadter, J., \& Greve, W. (1994). The Aging Self Stabilizing And Protective Processes. Developmental Review, 14 (1), 52-80. doi: DOI 10.1006/drev.1994.1003

[18] Brim, G. (1988). Losing And Winning. Psychology Today, 22 (9), 48-52.

[19] Atchley, R. C. (1991). The influence of aging or frailty on perceptions and expression of the self: Theoretical and methodological issues. In J. E. Birren and J. Lubben (Eds.), The concept and measurement of quality of life in the frail elderly (pp. 207-225). San Diego, CA: Academic Press.

[20] Shulan xu, zhiping wu, zhenyun wu, changhua sun. Age differences in self-concept in adulthood. Psychological science, 1997 (04): 289-293 + 382. (in Chinese)

[21] Wu Lanhua. The relationship between subjective well-being and self-concept in the elderly. Chinese journal of gerontology, 2010, 30 (13): 1873-1874. (in Chinese)

[22] Research group on the health and longevity of the elderly in China. Data set on the health and longevity of the elderly in China (1998). 2000: Peking University press, p. 6. (in Chinese) 